\title{
Edukasi Program "SADARI" Pada Wanita Usia Subur Desa Sungai Adong Kuala Dua Kecamatan Sungai Raya
}

\author{
Lidia Hastuti ${ }^{1}$, Tri Wahyuni ${ }^{2}$, Annisa Rahmawati ${ }^{3}$, Ridha Mardiani ${ }^{4}$, Nora Gracesara ${ }^{5}$, Selly $\mathrm{K}^{6}$

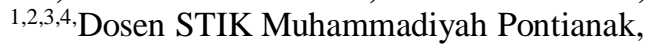 \\ ${ }^{5}$ Mahasiswa,STIK Muhammadiyah Pontianak \\ ${ }^{6}$ Praktisi \\ Email:lidya_zain@yahoo.com
}

Submitted : 16/08/2021

Accepted: 16/10/2021

Published: 19/11/2021

\begin{abstract}
Current women's health problems should receive serious attention. In Indonesia, the highest mortality rate is experienced by women of productive age (15-49 years). Women are very susceptible to various diseases, including breast cancer which is the number 2 killer disease in the world. Breast cancer is a disease that can affect anyone, especially women. Breast cancer is the most common cancer in women. Currently, cancer is the second leading cause of death. Incidence and death rates continue to increase in developing countries because early detection and treatment facilities are inadequate. The output of this activity is to increase knowledge and change behavior for early detection of breast cancer through BSE in Sungai Adong Kuala Dua village. The target of the activity is housewives in Sungai Adong village. Activity method by providing education and simulation of BSE techniques. The results showed that there was an increase in the pre-test score of knowledge about breast cancer from the pres test score of $30 \pm 8.2$ to $88 \pm 3.4$ during the post test. While knowledge of BSE techniques, the pre test score of $20 \pm 10.1$ increased to $80 \pm 2.6$ during the post test. For the skills on BSE techniques, the pre test score was $30 \pm 9.8$ increasing to $90 \pm 4.6$ at the time of the post test.
\end{abstract}

Keywords: breast cancer, WUS, BSE.

\begin{abstract}
Abstrak
Masalah kesehatan wanita saat ini harus memperoleh perhatian yang serius. Di Indonesia angka kematian tertinggi paling banyak dialami oleh wanita usia produktif (15-49 tahun). Wanita sangat rentan terhadap berbagai penyakit, termasuk penyakit kanker payudara yang menjadi penyakit pembunuh nomor 2 di dunia. Kanker payudara merupakan suatu penyakit yang dapat menyerang siapa saja, terutama wanita. Kanker payudara merupakan kanker yang paling banyak menyerang perempuan. Saat ini kanker menjadi penyebab kematian nomor dua. Angka kejadian dan kematian terus meningkat di negara berkembang karena fasilitas deteksi dini dan pengobatan belum memadai. Luaran dari kegiatan ini adalah untuk meningkatkan pengetahuan, dan perubahan perilaku untuk deteksi dini kanker payudara melalui SADARI di desa sungai Adong Kuala Dua. Sasaran kegiatan adalah ibu-ibu rumah tangga di desa Sungai Adong. Metode kegiatan dengan memberikan edukasi dan simulasi teknik SADARI. Hasil menunjukkan ada peningkatan skor pre test pengetahuan tentang penyakit kanker payudara dari skor pres test $30 \pm 8,2$ menjadi $88 \pm 3,4$ saat post test. Sementara pengetahuan tentang teknik SADARI, skor pre test 20 $\pm 10,1$ meningkat menjadi $80 \pm 2,6$ saat post test. Untuk keterampilan tentang teknik SADARI, skor pre test $30 \pm 9,8$ meningkat menjadi $90 \pm 4,6$ pada saat post test.
\end{abstract}

Kata Kunci :kanker payudara, WUS, SADARI.

\section{PENDAHULUAN}

Penyakit kanker merupakan salah satu penyakit tidak menular yang menjadi beban kesehatan diseluruh dunia. Kanker merupakan penyakit yang ditandai dengan adanya sel yang abnormal yang bisa berkembang tanpa terkendali dan memiliki kemampuan untuk menyerang dan berpindah antar sel dan jaringan tubuh. Badan kesehatan dunia/ World Health Organization menyebutkan kanker sebagai 
salah satu penyebab kematian utama di seluruh dunia (InfoDatin 2019).

Kanker adalah sekelompok besar penyakit yang dapat dimulai di hampir semua organ atau jaringan tubuh ketika sel abnormal tumbuh tak terkendali, melampaui batas biasanya untuk menyerang bagian tubuh yang berdekatan dan dapat menyebar ke organ lain yang biasa dikenal dengan metastasis. Secara umum, kanker merupakan penyebab kematian kedua di dunia. Kanker paru-paru, prostat, kolorektal, lambung dan hati adalah jenis kanker yang paling umum pada pria, sedangkan payudara, kanker kolorektal, paru-paru, serviks, dan tiroid adalah yang paling umum di antara wanita (https://www.who.int/healthtopics/cancer\#tab=tab_1).

Sekitar 9,6 juta kematian, atau satu dari enam kematian pada tahun 2018. Kanker adalah penyebab kematian kedua secara global dan bertanggung jawab atas sekitar 10 juta kematian per tahun. Secara global, sekitar 1 dari 6 kematian disebabkan oleh kanker. Sekitar 70\% kematian akibat kanker terjadi di negara berpenghasilan rendah dan menengah. Kanker adalah penyebab utama kematian di seluruh dunia, terhitung hampir 10 juta kematian pada tahun 2020. Pada tahun 2020, insiden kanker payudara menempati urutan pertama kasus kanker di dunia mencapai 2,26 juta kasus, berikutnya adalah kanker payudara (2,21 kasus) dan kanker usus besar dan rektum (1,93 juta kasus) dan beberapa kasus kanker lainnya (Ferlay et al., 2020).

Masalah kesehatan wanita pada saat ini harus memperoleh perhatian yang serius. Di Indonesia angka kematian tertinggi paling banyak dialami oleh wanita. Wanita usia produktif (15-49 tahun), wanita sangat rentan terhadap berbagai penyakit, termasuk penyakit kanker payudara yang menjadi penyakit pembunuh nomor 2 di dunia. Kanker payudara merupakan suatu penyakit yang dapat menyerang siapa saja, terutama wanita. Oleh karena itu, merupakan ancaman besar bagi kaum wanita. Meskipun bukan penyakit menular, sudah lebih dari 30 tahun kanker payudara menjadi suatu penyakit yang paling lazim dan paling ditakuti oleh para wanita. Kanker ini merupakan penyebab kematian kedua pada wanita, setelah kanker leher rahim pada wanita yang berusia 35-54 tahun.

Kanker payudara adalah suatu penyakit di mana terjadi pertumbuhan berlebihan atau perkembangan tidak terkontrol dari selsel jaringan payudara (Novianti dan Purnami, 2012). Kanker dapat menyerang semua lapisan masyarakat tanpa terkecuali dan tanpa mengenal status sosial, umur juga jenis kelamin. Remaja dan orang dewasa tak luput dari serangan mematikan ini. Namun dari data yang ada kaum wanita paling banyak terkena kanker (Kartikawati, 2012).

Angka kejadian penyakit kanker di Indonesia (136.2/100.000 penduduk) berada pada urutan 8 di Asia Tenggara, sedangkan di Asia urutan ke 23. Angka kejadian untuk perempuan yang tertinggi adalah kanker payudara yaitu sebesar 42,1 per 100.000 penduduk dengan rata-rata kematian 17 per 100.000 penduduk yang diikuti kanker leher rahim sebesar 23,4 per 100.000 penduduk dengan rata-rata kematian 13,9 per 100.000 penduduk (kemkes, 2019).

Berdasarkan Riskesdas Tahun 2018, diketahui bahwa prevalensi Kanker di Indonesia berkisar 1,79\%, sementara untuk Provinsi Kalimantan Barat prevalensi kanker sebesar 1,55\% . Jika berdasarkan umur yang terbanyak mengalami kanker adalah usia 55-64 tahun yaitu berkisar $4,62 \%$, dan perempuan lebih tinggi dibandingkan laki-laki untuk menderita Kanker (untuk perempuan 2,85\%, sedangkan Laki-laki 0,74\%). Kanker payudara dan kanker leher Rahim merupakan jenis kanker tertinggi pada pasien rawat inap maupun rawat jalan di seluruh RS di Indonesia, dengan jumlah pasien sebanyak 12.014 orang $(28,7 \%)$ 
untuk kanker payudara, dan kanker leher rahim 5.349 orang (12,8\%) (Dinkes Kalbar, 2019). Pengendalian dan dampak kanker payudara dapat dikurangi dengan meningkatkan kesadaran deteksi dini kanker payudara. Ketika kanker payudara terdeteksi dini dan diagnosis serta pengobatan yang mamadai tersedia, maka ada kesempatan kanker payudara dapat disembuhkan (InfoDatin, 2019).

Kubu Raya merupakan salah satu kabupaten pengembangan di provinsi Kalmantan Barat yang memiliki wilayah cukup luas yang memiliki sekitar 39 pulau dengan 118 Desa. Penelitian yang dilakukan Syarifah Gusmiranti di Desa Sungai Durian Kecamatan Sungai Raya Kubu Raya Tahun 2017 menemukan bahwa pengetahuan responden sebelum pendidikan kesehatan SADARI hanya 9\% yang berkategori baik, sedangkan sesudah pendidikan kesehatan pengetahuan responden yang berkategori baik menjadi $66 \%$. Sementara sikap responden sebelum pendidikan SADARI hanya $27 \%$ yang berkatergori baik, sedangkan sesudah pendidikan kesehatan sikap responden yang berkategori baik menjadi $72 \%$. Penelitian ini menunjukkan bahwa terdapat perubahan pengetahuan dan sikap SADARI antara sebelum dan sesudah pendidikan kesehatan.

Akses pelayanan kesehatan ibu dan anak dilaksanakan melalui pelayanan Puskesmas, dan dengan partisipasi masyarakat yang peduli terhadap kesehatan serta kesejahteraan ibu dan anak seperti Forum PUSPA (Partisipasi Publik untuk kesejahteraan Perempuan dan anak). Hasil penelitian membuktikan bahwa pemberian pendidikan kesehatan secara signifikan berpengaruh terhadap peningkatan pengetahuan dan sikap positif tentang SADARI. Hal ini sangat penting sebagai salah satu skrining untuk menemukan gejala dini penyakit kanker payudara agar tidak terlambat dalam penatalaksanaannya.

Akses pelayanan kesehatan tidak selalu menjadi masalah utama dalam kurangnya informasi. Tetapi kurangnya kebutuhan dan motivasi masyarakat untuk mencari informasi terkait penyakit-penyakit yang dapat dicegah atau dideteksi secara dini juga masih sangat rendah. Perlu proaktif dari tenaga kesehatan, lembaga sosial masyarakat dan pergruan tinggi untuk mengambil peran dalam meningkatkan kesejahteraan dan kesehatan wanita. Tim care for society STIK Muhammadiyah Pontianak, bersinergi dengan PUSPA Kab Kubu Raya, meningkatkan upaya pencegahan dan medeteksi dini kejadian kanker payudara dengan memberikan edukasi tentang penyakit kanker payudara serta simulasi Teknik SADARI kepada wanita usia subur di Desa kuala 2 Sungai Adong Kab Kubu Raya.

\section{TARGET DAN LUARAN}

Target care for society dari STIK Muhamamdiyah Pontianak adalah peningkatan pengetahuan masyarakat tentang penyakit kanker dan deteksi dini dengan teknik SADARI serta meningkatnya keterampilan masyarakat dalam melakukan teknik SADARI. Luaran adalah publikasi media masa atau publikasi jurnal Abdimas kesehatan.

\section{METODE PELKSANAAN}

Care for society yang dilakukan oleh tim bekerjasama dengan PUSPA dan Tim penggerak PKK desa Kuala Dua Kabupaten Kubu Raya. Kegiatan dilakukan dengan melakukan edukasi terhadap ibu-ibu di wilayah binaan PUSPA di Desa Sungai Adong. Pelaksanaan kegiatan dilakukan dengan beberapa tahapan yaitu, tahapan persiapan, pelaksanaan dan evaluasi.

Pada tahap persiapan tim melakukan survei awal lokasi kegiatan bersama dengan mitra. Selain itu juga mengumpulkan data dasar terkait dengan permasalahanpermasalahan dilapangan serta kontrak waktu untuk pelaksanaan kegiatan. Tim berkoordinasi dengan koordinator lapangan untuk pelaksanaan kegiatan. Dan Tim 
menyusun serta mempersiapkan materi, poster yang akan digunakan sebagai media yang bisa ditempel di tempat yang mudah diakses oleh ibu sebagai panduan pemeriksaan SADARI. Pada tahap pelaksanaan tim bersama mitra turun ke lokasi kegiatan untuk melakukan edukasi tentang kanker payudara dan melatih keterampilan dalam pemeriksaan SADARI.

Program Edukasi berisi pemberian materi tentang penyakit kanker payudara pada wanita dan simulasi pemeriksaan SADARI. Sebelum kegiatan dilakukan pre-test untuk mengukur kemampuan tentang penyakit kanker payudara. Pelaksanaan kegiatan berjalan sangat lancar, ibu-ibu sangat antusias dalam menerima materi dan sevara serius mendengarkan saat penjelasan tentang kanker payudara dan latihan dalam pemeriksaan SADARI.

Satu bulan setelah edukasi dilakukan post-test untuk mengukur peningkatan pengetahuan dan keterampilan pemeriksaan SADARI. Post-test dilakukan untuk mengevaluasi hasil kegiatan yang telah dilakukan. Tim akan menilai efektifitas edukasi dengan membandingkan perolehan skor pre-test dan post-test. Adapun gambaran alur intervensi yang dilaksanakan dapat dilihat pada Gambar 1 dibawah ini.

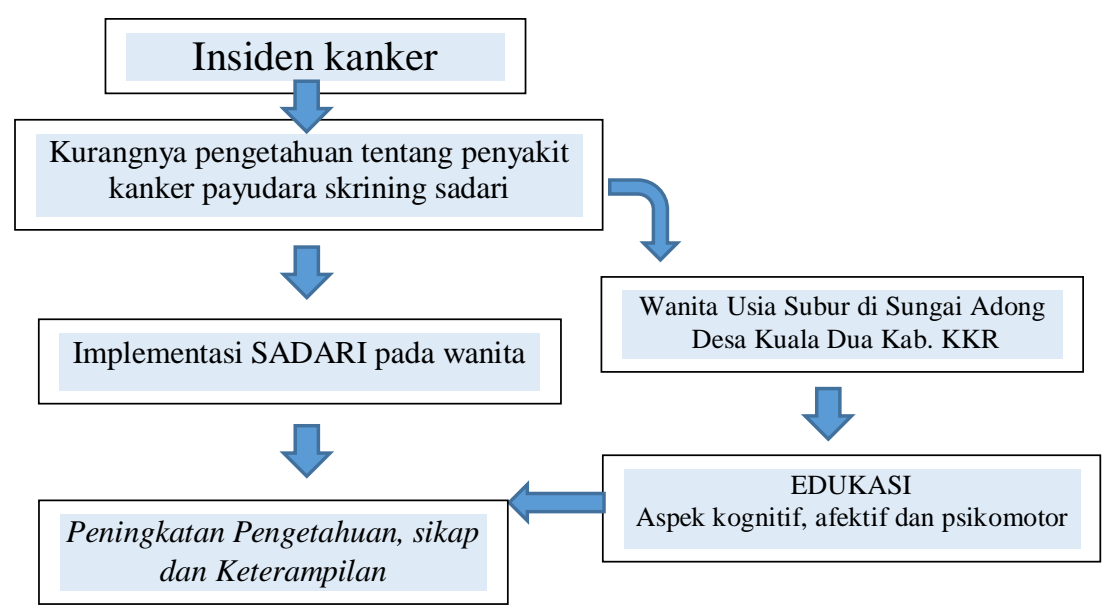

Gambar. 1 Alur intervensi care for society

\section{HASIL DAN PEMBAHASAN}

Kegiatan care for society dilakukan di Desa Sungai Adong, Kuala Dua Kabupaten Kubu raya, yang berjarak sekitar $15 \mathrm{~km}$ dari lokasi Tim. Lokasi dapat diakses dengan jalan darat. Merupakan salah satu desa dari 118 Desa yang berbatasan langsung dengan Ibu Kota Kab Kubu Raya. Akses ke lokasi kegiatan cukup mudah di jangkau, dengan mayoritas mata pencarian adalah petani dan buruh, selain pekerjaan lainnya. Lokasi kegiatan merupakan lokasi binaan PUSPA di Kab Kubu Raya. Adapun dokumentasi kegiatan dapat dilihat pada Gambar 2 di bawah ini.

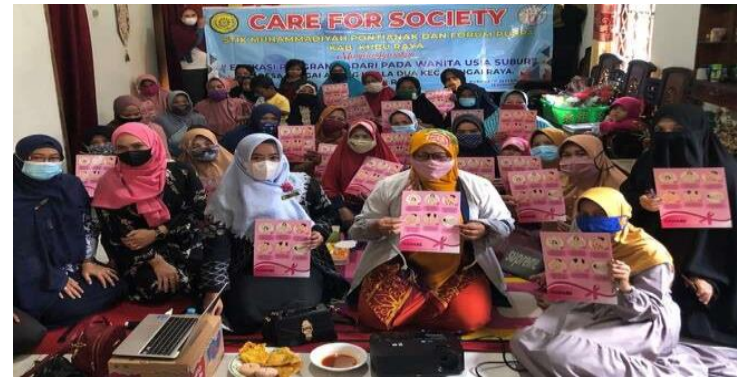

Gambar 2. Pelaksanaan Kegiatan

1. Karakteristik responden

Peserta dalam kegiatan ini adalah wanita usia subur yang berada dilokasi wilayah binaan PUSPA di Kab. Kubu Raya. Adapun karakteristik responden dalam 
kegiatan ini seperti yang terlihat pada Tabel 1 di bawah ini.

Tabel 1. Karakteristik responden

\begin{tabular}{lcc}
\hline Variabel & \multicolumn{2}{c}{$\mathrm{n}=30$} \\
\hline & $\mathrm{f}$ & $\%$ \\
\hline Usia (dalam tahun) & & \\
$21-30$ & 9 & $30 \%$ \\
$31-40$ & 10 & 33,3 \\
$41-50$ & 11 & 36,7 \\
\hline Pendidikan & & \\
Tidak Sekolah & 2 & 6,7 \\
Pendidikan Dasar & 3 & 10 \\
Pendidikan Menengah & 23 & 76,6 \\
Perguruan Tinggi & 2 & 6,7 \\
\hline Agama & & \\
Islam & 30 & 100 \\
Kristen & 0 & 0 \\
Hindu & 0 & 0 \\
Budha & 0 & 0 \\
\hline Status Pernikahan & & \\
Belum menikah & 1 & 3,3 \\
Menikah & 29 & 96,7 \\
Cerai & 0 & 0 \\
\hline Sumer Data pringe 2021
\end{tabular}

Sumber: Data primer 2021

Berdasarkan karakteristik responden seperti yang terlihat pada Tabel 1 menunjukkan bahwa, mayoritas responden berusia 41-50 tahun (36,7\%), dengan tingkat pendidikan menengah sebagai pendidikan yang paling banyak proporsinya, yaitu sebesar 76,6 \% berpendidikan Sekolah menengah (SMP dan SMA). Seluruh responden beragama Islam dan presentasi responden yang telah menikah sebesar $96,7 \%$.

2. Pengetahuan tentang kanker payudara

Pengetahuan tentang kanker payudara pada responden dapat sebelum dan setelah diberikan edukasi dapat dilihat pada Tabel 2 berikut ini

Tabel 2. Pengetahuan tentang penyakit kanker Payudana dan teknik SADARI pre

\begin{tabular}{lrc}
\multicolumn{3}{c}{ dan post } \\
\hline Pengetahuan & $\begin{array}{c}\text { Pre } \\
\text { test } \pm S D\end{array}$ & Post test $\pm S D$ \\
\hline $\begin{array}{l}\text { Penyakit } \\
\text { kanker }\end{array}$ & $30 \pm 8,2$ & $88 \pm 3,4$ \\
\hline
\end{tabular}

\begin{tabular}{|c|c|c|}
\hline payudara & & \\
\hline Teknik SADARI & $20 \pm 10,1$ & $80 \pm 2,6$ \\
\hline
\end{tabular}

Sumber: Data primer 2021

Berdasarkan Tabel 2 di atas, skor pre test pengetahuan tentang penyakit kanker payudara adalah $30 \pm 8,2$, sedangkan skor post test $88 \pm 3,4$. Sementara pengetahuan tentang teknik SADARI, skor pre test $20 \pm 10,1$ sedangkan skor post test $80 \pm 2,6$. Secara keseluruhan terjadi peningkatan skor pos test pada pengetahuan tentang penyakit kanker payudara dan teknik SADARI.

Keterampilan teknik SADARI

Tabel 3. Keterampilan tentang teknik SADARI pre dan post edukasi

\begin{tabular}{lcc}
\hline Pengetahuan & $\begin{array}{c}\text { Pre } \\
\text { test } \pm S D\end{array}$ & $\begin{array}{c}\text { Post } \\
\text { test } \pm S D\end{array}$ \\
\hline Keterampilan & $30 \pm 9,8$ & $90 \pm 4,6$ \\
Teknik & & \\
SADARI & \\
Sumber: Data primer 2021 \\
Berdasarkan Tabel 3 di atas, skor pre
\end{tabular}
test keterampilan tentang teknik SADARI, skor pre test $30 \pm 9,8$ sedangkan skor post test $90 \pm 4,6$. Ada peningkatan skor pos test keterampilan teknik SADARI.

\section{PEMBAHASAN}

Sosialisasi SADARI bagi semua wanita sebaiknya dimulai sejak usia subur, sebab $85 \%$ kelainan di payudara justru ditemukan pertama kali dikenali oleh penderita bila tidak dilakukan penapisan massal (Ekanita, P\& Khosidah, A, 2013). SADARI sebaiknya dilakukan setiap kali selesai menstruasi (hari ke-10 dari awal menstruasi), pemeriksaan dilakukan setiap bulan sejak umur 20 tahun (Rasjidi, 2010). SADARI sangat efektif sampai dengan $90 \%$ dalam mendeteksi kanker payudara termasuk pada wanita usia subur (Mikail, 2011 dalam Ekanita, P\& Khosidah, A, 2013).

\begin{tabular}{llrr}
\multicolumn{2}{c}{ Melakukan deteksi dini } & kanker \\
payudara dengan metode & SADARI \\
termasuk dalam kategori & tindakan \\
pencegahan penyakit. Hasil penelitian
\end{tabular}


melaporkan, semakin rutin melakukan SADARI maka dapat terhindar dari keterlambatan dalam melakukan pemeriksaan awal kanker payudara ke pelayanan kesehatan. Wanita yang tidak melakukan teknik SADARI mempunyai risiko 11,08 kali untuk mengalami keterlambatan melakukan pemeriksaan awal kanker payudara ke pelayanan kesehatan dibandingkan orang yang rutin melakukan deteksi dini SADARI setiap bulan (Dyanti dan Suariyani, 2016).

Penelitian lain melaporkan ada hubungan antara pengetahuan, sikap dengan SADARI dan merupakan salah satu upaya untuk mendeteksi terjadinya masalahmasalah pada payudara (Angrainy, 2017). Dengan melakukan deteksi payudara dengan teknik SADARI, wanita dapat mengetahui kondisi kesehatan payudara atau mengetahui dengan cepat kemungkinan masalah-masalah yang terjadi pada organ payudaranya. Dengan diketahui secara dini, maka penanganan terhadap masalah tersebut juga akan cepat.

Care for Society dilakukan pada 30 orang ibu rumah tangga, bekerja sama dengan Mitra PUSPA Kab. Kubu Raya. Pemberian edukasi tentang penyakit kanker payudara dan keterampilan dalam pemeriksaan SADARI sangat penting dalam mendeteksi secara dini penyakit kanker payudara. Kepedulian tentang kesehatan wanita khususnya pada kesehatn reproduksi perlu terus dilakukan, khusunya untuk meningkatkan pengetahuan, dan perilaku positif dalam memelihara dan meningatkan kesehatan reproduksinya.

Hasil intervensi edukasi pada ibu-ibu di Desa Kuala Dua, Sungai Adong di Kab. Kubu Raya menunjukkan bahwa ada peningkatan pengetahuan tentang penyakit kanker payudara, penngkatan pengetahuan tentang teknik SADARI dan keterampilan dalam melakukan teknik SADARI. Perlu terus dilakukan sosialisasi dan upaya-upaya peningkatan kesehatan wanita melalui pemberdayaan dan organisasi perempuan di masyarakat dan dapat bersinergi dengan perguruan tinggi.

\section{KESIMPULAN DAN SARAN}

\section{Kesimpulan}

Hasil edukasi program sadari pada wanita usia subur desa sungai adong kuala dua kecamatan sungai raya kabupaten kubu raya menunjukkan bahwa ada peningkatan pengetahuan tentang penyakit kanker payudara, penngkatan pengetahuan tentang teknik sadari dan keterampilan dalam melakukan teknik sadari.

\section{Saran}

Pemberian edukasi dan informasi tentang masalah kesehatan reproduksi perlu secara rutin dilakukan, berkoordinasi dengan lembaga sosial masyarakat, dan pelayanan kesehatan di masyarakat dan dapat bersinergi dengan perguruan tinggi.

\section{UCAPAN TERIMA KASIH}

Ucapan terima kasih kami sampaikan kepada Ketua STIK Muhammadiyah, Ketua Pusat Penelitian dan Pengabdian kepada masyarakat, Kepala Desa, Ketua penggerak PKK Desa Kuala Dua dan mitra PUSPA Kab. Kubu Raya.

\section{DAFTAR PUSTAKA}

Angrainy,R.A., Sugita, S., \& Susilowati, D. 2014. Hubungan pengetahuan sadari dengan minat deteksi dini kanker payudara pada remaja puteri kelas XI di SMA N 1 karangdowo klaten. Jurnal Kebidanan Indonesia.

Dyanti G. A.R., Suariyani, N. L. P. 2016. Faktor-faktor keterlambatan penderita kanker payudara dalam melakukan pemeriksaan awal ke pelayanan kesehatan. Universitas Negri Semarang Scientific Journal Ekanita, P., Khosidah, A. 2013. Hubungan antara pengetahuan dan sikap wus terhadap perilaku pemeriksaan payudara sendiri (SADARI). Jurnal Ilmiah Kebidanan, Vol. 4 No. 1. 
Ferlay J, Ervik M, Lam F, Colombet M, Mery L, Piñeros M, et al. 2020. Global Cancer Observatory: Cancer Today. Lyon: International Agency for Research on Cancer.

Info Datin. 2019. Beban kanker di indonesia. Kementrian Kesehatan RI. Jakarta.

Kartikawati., Erni.2012. Awas!!! Bahaya Kanker Payudara \& Kanker Serviks (Edisi Pertama). Bandung: Buku Baru.

Kemenkes.RI. 2015. Panduan Nasional Penanganan Kanker Kanker Payudara. Komite Nasional Penanggulangan Kanker (KPKN).

Novianti, F.A., Purnami, S.W. 2012. Analisis diagnosis pasien kanker payudara menggunakan regresi logistik dan support vector machine (svm) berdasarkan hasil mamograf. Jurnal sains dan seni ITS Vol. 1, No. 1. . ISSN: 2301-928.

Rasjidi, I. 2010. Kanker Pada Wanita. PT Elex Media Komputindo. Jakarta.

Dinkes Kalbar. Riskesdas 2018. 2019. (https://dinkes. Kalbarprov. go.id /wp-content/uploads/2019/03/HasilUtama-RISKESDAS-2018.pdf)

https://www.kemkes.go.id/article/view/190 20100003/hari-kanker-sedunia2019.html 